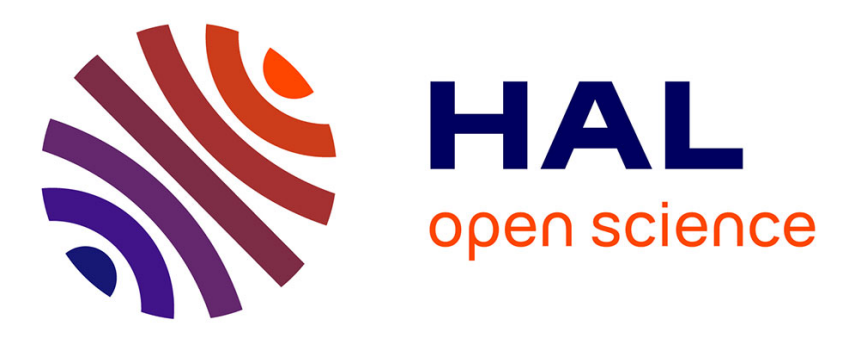

\title{
Indonesian throughflow control of the eastern equatorial Pacific biogeochemistry
}

Thomas Gorgues, Christophe E. Menkès, Olivier Aumont, Yves Dandonneau, Gurvan Madec, Keith B. Rodgers

\section{- To cite this version:}

Thomas Gorgues, Christophe E. Menkès, Olivier Aumont, Yves Dandonneau, Gurvan Madec, et al.. Indonesian throughflow control of the eastern equatorial Pacific biogeochemistry. Geophysical Research Letters, 2007, 34, pp.L05609. 10.1029/2006GL028210 . hal-00153326

\section{HAL Id: hal-00153326 \\ https://hal.science/hal-00153326}

Submitted on 16 Jul 2007

HAL is a multi-disciplinary open access archive for the deposit and dissemination of scientific research documents, whether they are published or not. The documents may come from teaching and research institutions in France or abroad, or from public or private research centers.
L'archive ouverte pluridisciplinaire HAL, est destinée au dépôt et à la diffusion de documents scientifiques de niveau recherche, publiés ou non, émanant des établissements d'enseignement et de recherche français ou étrangers, des laboratoires publics ou privés. 


\section{Indonesian Throughflow control of the eastern equatorial Pacific biogeochemistry.}

T. Gorgues (1), C. Menkes (2), O. Aumont (3), Y. Dandonneau (4), G. Madec (5), K. Rodgers (6)

(1) LOCEAN, UPMC, Case 100, 4 place Jussieu, 75252 Paris, France.

(2) LOCEAN, IRD, BP A5 Nouméa, 98848 Cedex, New Caledonia

(3) LOCEAN, IRD, Centre IRD de Bretagne, BP 70, 29280 Plouzané, France.

(4) LOCEAN, IRD, Case 100, 4 place Jussieu, 75252 Paris, France.

(5) LOCEAN, CNRS, Case 100, 4 place Jussieu, 75252 Paris, France.

(6) AOS Program, Princeton University, Princeton, New Jersey 08544-0710, USA. 
Abstract

Two model simulations were performed to address the influence of the Indonesian Throughflow (ITF) on the biogeochemical state of the equatorial Pacific. A simulation where the ITF is open is compared with an experiment where it is closed, and it is first shown that the impacts on the physical circulation are consistent with what has been found in previous modelling studies. In terms of biochemistry, closing the ITF results in increased iron concentration at the origin of the Equatorial Undercurrent (EUC). But the $11 \mathrm{~Sv}$ of water otherwise transferred to the Indian Ocean remain in the equatorial Pacific, which result in a 30m deepening of the thermocline/ferricline in the eastern Pacific. This deepening decreases the iron concentration of the equatorial wind driven upwelled water and cancels the iron increase advected by the EUC. The iron decrease of the equatorial upwelled water leads to decrease primary production by $15 \%$ along the equator. 
There is a growing consensus that low iron concentration in surface waters, in conjunction with grazer control of phytoplankton, imposes a first order control on the rate of biological production [Martin et al., 1991; Coale et al., 1995, Behrenfeld et al., 1996] in the eastern equatorial Pacific, with limitation by silicate concentration only imposing a second-order limitation [Blain et al., 1997; Nelson D., personal communication]. These conditions help to explain why the Equatorial Pacific is known to be a High Nutrient Low Chlorophyll (HNLC) region. It is known that the upwelled water from the EUC is the primary source of nitrate [Toggweiler and Carson, 1995] and iron [Gordon et al., 1997] in the eastern equatorial Pacific.

Using data from the Western Equatorial Pacific Ocean Circulation Study (WEPOCS II) survey, Tsuchiya et al., [1989] showed that the majority $(1 / 2$ to $2 / 3)$ of the water feeding the EUC in the western Pacific is Southern Hemisphere Water (SHW). Hirst and Godfrey, [1993] and Rodgers et al., [1999] used model experiments to argue that if the Indonesian Throughflow (ITF) transport is blocked, the Northern Hemisphere Water (NHW) component of the EUC will become dominant. For isopycnal density horizons corresponding to the EUC, NHW tends to be cooler and fresher than SHW for the mean circulation [Rodgers et al., 1999]. Dugdale et al., [2002] have used data from WEC88 [Carr et al., 1992] and US JGOFS EqPac [Murray et al., 1995] to show that a similar asymmetry exists for nitrate and silicate concentrations, with higher concentrations for the NHW. Iron also exhibits an asymmetry, with higher iron concentration in the SHW component [Mackey et al., 2002]. Thus the treatment of the ITF boundary condition 
could have at least for the mean state a potential impact on the biogeochemical concentrations within the EUC and in particular iron concentration.

The NHW source of ITF water is comparatively fresher and colder than the SHW source [Ffield and Gordon, 1992]. Then, with a closed ITF, more cold NHW are supplied into the EUC [Rodgers et al., 1999], so that one expects the equatorial thermocline to cool. However, simulations with a variety of models [e.g. Hirst and Godfrey, 1993; Murtugudde et al., 1998; Rodgers et al., 1999; Lee et al., 2002] indicate that closing the ITF warms the Pacific Ocean, despite the increased proportion of colder NHW within the EUC. Thus the cooling of EUC isopycnals is more than compensated by a deepening of the thermocline/pycnocline associated with closing the ITF [Hirst and Godfrey, 1993; Rodgers et al., 1999; Lee et al., 2002].

In this study we are interested in identifying the extent to which such compensation does or does not occur with biogeochemistry. It is our intention to address the sensitivity of equatorial biogeochemistry to the boundary condition posed by the ITF. This is relevant to our more general interest in the dynamical controls on the supply of nutrients to the upwelling region in the eastern equatorial Pacific. An additional goal is to provide an estimate of the bias associated with the use of a Pacific-only domain in modelling studies of equatorial Pacific biogeochemistry [i.e. the studies of Chai et al., 1996; Radenac et al., 2001; Christian et al., 2002].

\section{Model Description}

We use the Ocean General Circulation Model, OPA [Madec et al, 1998], in its ORCA2 global configuration. Zonal resolution is $2^{\circ}$, and meridional resolution is $2 \times \cos$ (latitude), increasing to $0.5^{\circ}$ at the equator, and there are 31 vertical levels with a spacing of 10 
meters in the upper 150 meters, increasing to 500 meters in the deep ocean. We have performed two model runs: the reference simulation with the default geometry of the ORCA2 grid (hereafter, REF), and a simulation where we have blocked the ITF by closing the Timor Strait (Fig. 1A-B), which in the model bathymetry connects the Indian and Pacific Oceans (this run is referred to as ITC). For both simulations the initial state is taken from the World Ocean Atlas 1998 (WOA98) [Antonov et al., 1998; Boyer et al., $1998]$ temperature and salinity climatologies, and spun up for 100 years using climatological forcing fields derived from a combination of ERS1-2 and TAO (Tropical Atmosphere Ocean project) stresses. Heat and freshwater fluxes are calculated using bulk formulas, which use the climatology from the National Centers for Environmental Prediction reanalysis (NCEP-1) [Kalnay et al., 1996].

The OPA output files (the 3-D velocities and vertical diffusion coefficients) are then used in offline mode by the food-web/biogeochemistry model, the Pelagic Interaction Scheme for Carbon and Ecosystem Studies (PISCES) [Aumont and Bopp, 2006]. PISCES describes the biogeochemical cycles of carbon and of the main nutrients (N, P, Si and Fe) which limit phytoplankton growth. The model has twenty-four compartments, with two phytoplankton size classes (nanophytoplankton and diatoms), zooplankton (microzooplankton and mesozooplankton) and 2 sinking particles classes (large and small). Phytoplankton growth is limited by external concentrations of iron, nitrate, silicate, ammonium, and phosphate. For all living compartments, a constant Redfield ratio is used for $\mathrm{C}, \mathrm{N}$ and $\mathrm{P}$, but the internal content in Fe and $\mathrm{Si}$ of phytoplankton are prognostically simulated as a function of the external concentrations in nutrients. Details on iron modelling in PISCES can be found in Aumont and Bopp, [2006]. PISCES is initialized by the Conkright et al., [1998] climatology and by climatologically varying 
model fields for some of the biogeochemical components, in particular iron. The offline biogeochemical model is run for fifty years in order to reach an approximate biogeochemical steady state.

\section{Model Validation}

In REF, the transport through the ITF from the Pacific Ocean to the Indian Ocean is 11

Sv. This value falls within the range of previous estimates based on field measurements [e.g. Godfrey, 1996; MacDonald et al., 1998] and is close to what is found with other physical models [e.g. Hirst and Godfrey, 1993; Lee et al., 2002]. In terms of its structure and amplitude, the sea surface temperature for the REF simulation is in good agreement with the Advanced Very High Resolution Radiometer data, although surface waters in the warm pool have a warm bias of approximately $0.5^{\circ} \mathrm{C}$ (not shown). The zonal current profile at the equator (not shown) resembles the TAO mooring data except near $170^{\circ} \mathrm{W}$ where the EUC is slightly underestimated.

The range of density in figure $2 \mathrm{C}-\mathrm{D}\left(\sigma_{\theta}=23.5 \mathrm{~kg} \cdot \mathrm{m}^{-3}\right.$ to $\left.\sigma_{\theta}=25.5 \mathrm{~kg} \cdot \mathrm{m}^{-3}\right)$ brackets the density of the EUC core for both simulations. The location of the vertical profiles are $\left(5^{\circ} \mathrm{S}-9^{\circ} \mathrm{S} ; 150^{\circ} \mathrm{E}-155^{\circ} \mathrm{E}\right)$ for the SHW, $\left(3^{\circ} \mathrm{N}-6^{\circ} \mathrm{N} ; 150^{\circ} \mathrm{E}-155^{\circ} \mathrm{E}\right)$ for the NHW and $\left(1^{\circ} \mathrm{S}-\right.$ $1^{\circ} \mathrm{N} ; 162^{\circ} \mathrm{E}-168^{\circ} \mathrm{E}$ ) for the EUC. Modelled and observed salinity in the SHW and in the NHW (figure 2C and 2D) are very close arguing for a realistic representation of the water properties. In the model as well as in the WOA98 data, the NHW are colder and fresher than the SHW. The salinity profile for the EUC shows good agreement with the one from WOA98 data demonstrating that the ratio in the transport of water from the SHW and the NHW into the EUC is consistent. Indeed, with an open ITF the EUC is principally fed by 
SHW and for a smaller part by NHW [Tsuchiya et al., 1989], so that its salinity structure is closer to that of the SHW.

Meridional sections (Fig. 2E-F) at $155^{\circ} \mathrm{E}$ (black line in Fig. 2A) show that despite a weaker than observed nitrate concentration, the NHW has a stronger nitrate concentration than the SHW in REF simulation (Fig. 2E), which is in agreement with previously published result [e.g. Dugdale et al., 2002]. Figure 2F shows that contrary to nitrate, the SHW has a stronger iron concentration than the NHW. These results are coherent with in situ data from Mackey et al., [2002].

When compared to the SeaWiFS chlorophyll data (Fig. 2A), and despite the poor representation of the coastal concentration due to the coarse resolution of the model, the REF simulation shows reasonable chlorophyll patterns over the equatorial Pacific (Fig. 2B). A validation of the vertical profile of iron can be found in Gorgues et al., [2005].

\section{Results}

The $20^{\circ} \mathrm{C}$ isotherm is $30 \mathrm{~m}$ deeper along the equator for the ITC simulation than for the REF simulation in the eastern Pacific (Fig. 3D), and this result is consistent with the results of the study of Lee et al., [2002]. The watermass characteristics of the SHW and the NHW do not change between the two experiments. Thus the salinity decrease in the EUC (Fig. 2D) is due to the increased presence of NHW. Hence, the watermass characteristics of the EUC shift towards the characteristics of the NHW component when ITF is closed. Closing the ITF also reduce the strength of the New Guinea UnderCurrent (NGUC) by almost 50\% while the Mindanao current increases slightly (10\%) (Fig. 1AB). That result is also consistent with the findings of Lee et al., [2002]. 
In the EUC range of density ( $\sigma=23.5$ to 25.5 ), the most striking result is an iron (Fig. 1A) and nitrate (Fig. 1B) concentration increase north of New Guinea in the SHW, while in the NHW the concentrations increase only in a narrow band near the coastline of the ITF. Moreover, closing the ITF increases the iron and nitrate concentrations by $30 \%$ in the EUC downstream to $155 \mathrm{~W}$ (Fig. 1A-B).

We have focused on the euphotic layer (defined here as the depth to which $0.1 \%$ light is available), which is the relevant depth for marine production. Figure $3 \mathrm{~A}$ shows the effect of closing the ITF on the mean chlorophyll concentration over the euphotic zone. The decrease reaches $0.07 \mathrm{mg} \cdot \mathrm{m}^{-3}$ (up to $15 \%$ of the maximum chlorophyll) at the equator $\left(1^{\circ} \mathrm{N}-1^{\circ} \mathrm{S} ; 110^{\circ} \mathrm{W}-90^{\circ} \mathrm{W}\right)$ and an equal decrease is observed on the southern border of the chlorophyll-rich region of the REF simulation (Fig. 2B), but not on the northern border.

Despite the iron increase in the western Pacific (Fig. 1A), closing the ITF entails a marked decrease in iron at the equator (Fig. 3B), up to $0.015 \mathrm{nM}(20 \%)$, over the euphotic zone. Iron concentration also increases in the North Equatorial Counter Current (NECC), near the Peru/Chile coast and near the Californian coast (Fig. 3B). Unlike iron, nitrate (Fig. 3C) shows a broader equatorial decrease which matches the relatively chlorophyll rich region and there is no significant increase elsewhere.

\section{Discussion}

Several studies have assessed the modification of the circulation of the Pacific Ocean caused by closing the ITF. These studies concur on the main dynamical impacts of this closure. The deepening of the thermocline is due to the accumulation over the Pacific of warm water which would otherwise have been siphoned into the Indian Ocean. Additionally, our simulations highlight a modification of the hemispheric origin of the 
water feeding the EUC. In the REF simulation, the water in the EUC comes largely from the Southern Hemisphere, whereas in the ITC simulation, the EUC water is mainly supplied from the north. This is evident in the shift of the EUC towards NHW watermass characteristics when the ITF is closed (Fig. 2D), and consistent with the results of previous modelling studies [Rodgers et al., 1999]. Interestingly, the iron and nitrate increase which occur north of New Guinea (Fig. 1A-B), within the EUC range of density, is concomitant with a local deepening (10 meters) of the being injected which prevent the decrease of iron and nitrate on z-levels that would normally be associated with the deepening of the thermocline/pycnocline. Then, in ITC and along given isopycnals corresponding to the EUC, the water comes from greater depth and has higher concentrations of iron and nitrate. Despite a weaker NGUC, that increase in iron and nitrate concentrations in the SHW is finally advected on isopycnal surfaces to the EUC downstream to $155 \mathrm{~W}$, where the iron and nitrate concentrations increase.

In contrast, iron and nitrate concentrations in the eastern equatorial Pacific decrease in the euphotic zone when the ITF is closed (Fig. 3B). Indeed, in the central and eastern Pacific, the 30 meter deepening of the thermocline/pycnocline causes a deepening of the ferricline/nitracline because, unlike the New Guinea region, there are no nutrient sources such as coastal sources which could prevent the iron or nitrate decrease by nutricline deepening. In this region, the nutricline deepening is directly linked to the additional amount of water from the closed ITC, as for the thermocline/pycnocline deepening. Finally, the wind driven dynamics upwells waters with lower iron and nitrate concentrations to the euphotic layer. EUC concentration increase in iron and nitrate in the 
western Pacific does not compensate for the deepening of the thermocline/ferricline (Fig. 3D) that reduces the nutrient sources in the east. Because iron is the limiting nutrient (Fig. 3C), its equatorial decrease is confined to a narrow band (Fig. 3B) near its source region (where the phytoplankton uptake has not yet depleted the water in iron) since the nitrate which has a longer residence time displays a broader negative pattern (Fig. 3C). When closing the ITF, the iron decrease in the euphotic zone of the eastern equatorial Pacific explains the decrease in chlorophyll (Fig. 3A). In the southern hemisphere, the decrease in nitrate concentration increases the width of the nitrate-limited area (contour in Fig. 3A), which in turn drives the chlorophyll decrease in the southern hemisphere (Fig. 3A). North of the equator, for both simulations, high nitrate concentrations from the equatorial upwelling are bounded by the strong convergence that occurs near $5^{\circ} \mathrm{N}$ between the South Equatorial Current (SEC) and the nitrate-poor waters of the NECC. In REF and ITC, south of the equator, the convergence region only occurs near $20^{\circ} \mathrm{S}$ [Toggweiler and Carson, 1995]. Then, south of the equator, nitrate-rich waters from the equator are depleted by phytoplankton uptake before reaching the convergence zone which is not the case north of the equator. Hence it is the meridional asymmetry in the zonal circulation that explains the asymmetrical nitrate decrease and the related decrease in chlorophyll more strongly visible in the southern hemisphere (Fig. 3A-C). The weak iron increase (Fig. 3B) in ITC in these regions has thus no impact on phytoplankton concentration (Fig. 3A) because it occurs in a region where nitrate is the limiting element (Fig. 3C) in ITC simulation.

Off the equator, the behaviour of iron is more complicated. Figure $3 \mathrm{~B}$ shows a strong increase in iron concentration in the western Pacific warm pool and in the NECC. In the ITC simulation, the iron rich water usually exported to the Indian Ocean is constrained to 
remain in the Pacific warm pool and is advected eastward by the NECC (Fig. 3B) without being depleted by phytoplankton because of nitrate limitation (Fig. 3C). Due to the nitrate limitation of these regions (Fig. 3C), the increased iron concentration has no effect on the ecosystem productivity (Fig. 3A). Finally, near the coasts of Peru and Costa-Rica, the deepening of the thermocline/nitracline associated with the closure of the ITF results in a depletion of the nitrate concentration of waters entering the euphotic zone and this region becomes nitrate limited (Fig. 3A). This limitation results in a decrease in chlorophyll concentration which in turn decreases the iron uptake by phytoplankton, which leads to an increase in iron concentration (Fig. 3B).

All these results are robust to changes in the wind stress field used. We have repeated the two experiments using the NCEP reanalysis [Kalnay et al., 1996] wind stresses. These experiments reveal the same patterns of biogeochemical perturbations in the eastern equatorial Pacific when closing the ITF (not shown), with a $10 \%$ equatorial decrease of chlorophyll due to a slightly weaker response of the thermocline depth (up to $-20 \mathrm{~m}$ instead of $-30 \mathrm{~m})$. We have also tested the sensitivity to different sets of bathymetric modifications to close the ITF, and found that the biogeochemical response is insensitive to such changes. Finally, a more realistic nitrate distribution in the western Pacific (Fig. $2 \mathrm{E}$ ), could, by the stronger nitrate increase from the NHW contribution to the EUC in the ITC simulation, offset partially the decline of nitrate and chlorophyll south of the equator (region limited by nitrate) but should not affect the equatorial biological production decrease due to the stronger iron equatorial limitation.

\section{Conclusions}


A model has been used to show that closing the ITF can lead to a $15 \%$ decrease in primary productivity in the upwelling region of the eastern equatorial Pacific. This sensitivity to a nonlocal boundary condition is large, and is the result of two competing effects. First, closing the ITF results in increased iron concentration on isopycnal surfaces corresponding to the EUC. Additionally, closing the ITF results in a dynamical deepening of the thermocline/pycnocline, which reduces the supply of iron to the upwelling region and more than compensates the iron increase within the EUC. Thus, pacific only model domains [Chai et al., 1996; Christian et al., 2002; Radenac et al., 2001] would likely be biased by a decrease in primary productivity due to this nonlocal boundary condition if the ITF is not properly treated. Closing the ITF should have even broader implications for model biases. Indeed, in our model runoff and sedimental remineralization in the western Pacific lead to diminish the impact of closing the ITF by increasing the iron and nitrate concentrations on EUC isopycnals. Thereby, models which don't account for river nutrient inputs or sedimental remineralization may exhibit a larger bias in iron and nitrate in the eastern Pacific. In our study we have reported the changes in the mean state due to the closing of the ITF. However, a closed ITF can also significantly impact the variability, as a deeper mean ferricline/nitracline can diminish the biogeochemical response to vertical displacements of the ferricline/nitracline in the eastern Pacific.

More generally, the results presented here have potential implications for understanding the effects of variability in circulation on biogeochemistry and ecosystems in the upwelling region. This study could be seen as a unique way to test the biogeochemical consequences of any changes in the mean state of the Pacific thermocline depth. For example, recent studies have described significant variability in the depth of the thermocline in the eastern equatorial Pacific on interannual to decadal timescales [e.g. 
McPhaden et al., 2002]. A deep thermocline in the eastern Equatorial Pacific will result in decreased production while a shallow thermocline will be associated with more productive ecosystems. However, a deepening of the thermocline in the east during a warm period is typically associated with a shallowing of the thermocline in the western Pacific, which is not the case when the ITF is closed. Due to this shoaling in the west, the EUC may advect waters with lower concentrations of iron and nitrate to the eastern equatorial Pacific, as the shoaling in the west can impact the concentration of biogeochemical tracers in that region. This could reinforce the biological production decrease caused mainly by the deepening of the thermocline/pycnocline in the eastern equatorial Pacific. Such an impact on the biogeochemical state of the Pacific has been shown in some observationally-based studies [e.g. Chavez et al. 2003].

This work underscores the importance of a skilful representation of the thermocline /pycnocline in the equatorial Pacific. Our study implies that the concentration of nutrient in the source regions of the EUC, in the western Pacific, is a second order mechanism. Acknowledgement: The authors thank our reviewers for constructive comments which greatly improve this manuscript.

\section{References}

Antonov, J. I., Levitus, Boyer, Conkright, O’Brien, Stephens (1998), World Ocean Atlas 1998, Vol. 2:Temperature of the Pacific Ocean, NOAA Atlas NESDIS 28, U.S. Global Biogeochem. Cycles, 20, GB2017, doi:10.1029/2005GB002591. 
Behrenfeld, M.J., Bale, Kolber, Aiken, Falkowski (1996), Confirmation of iron limitation of phytoplankton photosynthesis in the equatorial Pacific Ocean, Nature, 383, 508-511. Blain, S., Leynaert, Treguer, Chretiennot-Dinet, Rodier, (1997), Biomass, growth rates and limitation of equatorial Pacific diatoms, Deep-Sea Research I 44 (7), 1255-1275. Atlas 1998 Vol. 5: Salinity of the Pacific Ocean, NOAA Atlas NESDIS 30, U.S. Gov. Printing Office, Wash., D.C., 166 pp.

Carr, M., Oakey, Jones, and Lewis (1992), Hydrographic patterns and vertical mixing in the equatorial Pacific along $150^{\circ} \mathrm{W}$, J. Geophys. Res., 97(C1), 611-626.

Chai, F., Lindley, Barber (1996), Origin and maintenance of a high nitrate condition in the equatorial Pacific, Deep Sea Research II, 43(4-6), 1031-1064.

Chavez, F. P., Ryan, Lluch-Cota, Niquen (2003), From Anchovies to Sardines and Back: Multidecadal Change in the Pacific Ocean, Science, 299, 217-221.

Christian, J. R., Verschell, Murtugudde, Busalacchi, McClain (2002), Biogeochemical modelling of the tropical Pacific Ocean. Part I: Seasonal and interannual variability, Deep Sea Research II, 49, 509-543.

Coale, K.H., Fitzwater, Gordon, Johnson, Barber (1996), Control of community growth and export production by upwelled iron in the equatorial Pacific Ocean, Nature, 379, $621-624$.

Conkright, M., O’Brien, Levitus, Boyer, Antonov, Stephens (1998), World Ocean Atlas 1998, Vol. 11: Nutrients and Chlorophyll of the Pacific Ocean, US Dept. of Commerce, Washington, 245pp.

Dugdale, R.C., A.G. Wischmeyer, F.P. Wilkerson, R.T. Barber, F. Chai, M.-S. Jiang, T.H. Peng (2002), Meridional asymmetry of source nutrients to the equatorial Pacific 
upwelling ecosystem and its potential impact on ocean-atmosphere CO2 flux; a data and modeling approach, Deep-Sea Research II, 49, 2513-2531.

Ffield, A., A. L. Gordon, (1992), Vertical mixing in the Indonesian thermocline, J. Phys.

Oceanogr., 22, 184-195.

Godfrey, S. (1996), The effect of Indonesian throughflow on ocean circulation and heat exchange with the atmosphere, J. Geophys. Res., 101, 12217-12237.

Gordon, R.M., K.H. Coale, K.S. Johnson (1997), Iron distributions in the equatorial Pacific: implications for new production, Limnology and Oceanography, 42, 419-431.

Gorgues, T., Menkes, Aumont, Vialard, Dandonneau, Bopp (2005), Biogeochemical impact of tropical instability waves in the equatorial Pacific, Geophys. Res. Lett., 32, L24615.

Hirst, A.C., and J.S. Godfrey (1993), The role of Indonesian throughflow in a global ocean GCM. J. Phys. Oceanogr., 23, 1057-1086.

Kalnay, E.C., et al. (1996), The NCEP/NCAR reanalysis project, Bull. Am. Meteor. Soc., $77,437-471$.

Lee, T., I. Fukumuri, Menemenlis, Xing, Fu (2002), Effects of the Indonesian Throughflow on the Pacific and Indian Oceans, Journal of Phys. Oceanography, Vol. 32, No. 5, 1404-1429.

Macdonald, A.M. (1998), The global ocean circulation: A hydrographic estimate and regional analysis, Progress in Oceanography, Vol. 41, Pergamon, 281-382. riverine or hydrothermal source for iron in the Equatorial Undercurrent?, Deep Sea Research I, 49, 877-893(17). 
Madec, G., et al. (1998), OPA 8.1 Ocean General Circulation Model reference manual, Notes du Pole de Modélisation de l'Institut Pierre-Simon Laplace, 11, 91 pp. Martin, J. H., Gordon, Fitzwater (1991), The Case for Iron, Limnol. Oceanogr., 36, $1793-1802$.

McPhaden, M.J., D. Zhang (2002), Slowdown of the meridional overturning circulation in the upper Pacific Ocean, Nature, 415, 603-608.

Murray, J.W., E. Johnson, C. Garside (1995), A US JGOFS process study in the equatorial Pacific (EqPac): An introduction, Deep-Sea Research II, 42, 275-293.

Murtugudde, R., A.J. Busalacchi, and J. Beauchamp (1998), Seasonal-to-interannual effects of the Indonesian throughflow on the tropical Indo-Pacific basin, J. Geophys. Res., 103, 21425-21441.

Radenac, M.-H., C. Menkes, J. Vialard, C. Moulin, Y. Dandonneau, T. Delcroix, C. Dupouy, A. Stoens, P.-Y. Deschamps (2001), Modeled and observed impacts of the 1997-1998 El Niño on nitrate and new production in the equatorial Pacific, Journal of Geophysical Research, Volume 106, Issue C11, 26879-26898.

Rodgers, K.B., Cane, Naik, Schrag (1999), The role of the Indonesian Throughflow in equatorial Pacific thermocline ventilation, J. Geophys. Res., 104, 20551-20570.

Toggweiler, J.R., Carson (1995), What are upwelling systems contributing to the ocean's carbon and nutrient budgets? In: Summerhayes, Emeis, Angel, Smith, Zeitzschel, (Eds.), Upwelling in the Ocean: Modern Processes and Ancient Records. Wiley, 337-360.

Tsuchiya, M., Lukas, Fine, Firing and Lindstrom (1989), Source Waters of the Pacific Equatorial Undercurrent, Prog. Oceanogr., 23, 101-147.

Walsh, J.J. (1976), Herbivory as a Factor in Patterns of Nutrient Utilization in the Sea, Limnology and Oceanography, Vol. 21, No. 1, 1-13. 
Fig 1: (A) Difference (ITC-REF) of the mean iron concentration (nM) between the isopycnal surfaces $\sigma_{\theta}=23.5 \mathrm{~kg} \cdot \mathrm{m}^{-3}$ and $\sigma_{\theta}=25.5 \mathrm{~kg} \cdot \mathrm{m}^{-3}$. Vectors represent the currents $\left(\mathrm{m} . \mathrm{s}^{-}\right.$ ${ }^{1}$ ) averaged between the previous isopycnal surfaces for REF. (B) As for A but with nitrate $(\mu \mathrm{M})$ rather than iron and with ITC currents rather than REF currents. The black region is added in the Timor strait to close the ITF for the ITC simulation.

Fig 2: (A) Mean SeaWiFS chlorophyll concentration (mg.m ${ }^{-3}$ ) over the 1999-2004 period depth of the $20^{\circ} \mathrm{C}$ isotherm plotted over. (C) Salinity versus density diagram for the SHW (cross), the NHW (stars) and the EUC waters (triangle) for the WOA98 data. (D) As for $\mathrm{C}$, but for our two simulations ( $\mathrm{REF}=$ blue; $\mathrm{ITC}=\mathrm{red})$. (E) Meridional section at $155^{\circ} \mathrm{E}$ of the nitrate concentration $(\mu \mathrm{M})$ for the REF simulation (colors) and the data from the WOA98 (black lines). (F) Meridional section at $155^{\circ} \mathrm{E}$ of the iron concentration (nM) with isopycnal surfaces from REF (black lines) and from ITC (dashed lines).

Fig 3: (A) Difference (ITC-REF) of chlorophyll concentration (mg.m ${ }^{-3}$ ) averaged over the depth of the euphotic zone. Contour indicates the change in areal extent (ITC-REF) of the region where nitrate is the limiting nutrient. (B) As for A, but for iron (nM) concentration. The contour of $0.03 \mathrm{mg} \cdot \mathrm{m}^{-3}$ of chlorophyll difference is added. (C) As for $\mathrm{B}$, but for nitrate $(\mu \mathrm{M})$ rather than iron and with vertical (horizontal) hatch marks which indicate the iron (nitrate) limited region in the REF simulation. (D) Vertical section at the equator of the temperature difference (ITC-REF). Closed contours show the EUC zonal velocity $\left(\mathrm{m} . \mathrm{s}^{-1}\right)$, and contour intervals are $0.25 \mathrm{~m} \cdot \mathrm{s}^{-1}$. The black (red) dashed lines show the $20^{\circ} \mathrm{C}$ isotherm depth from REF (ITC). 


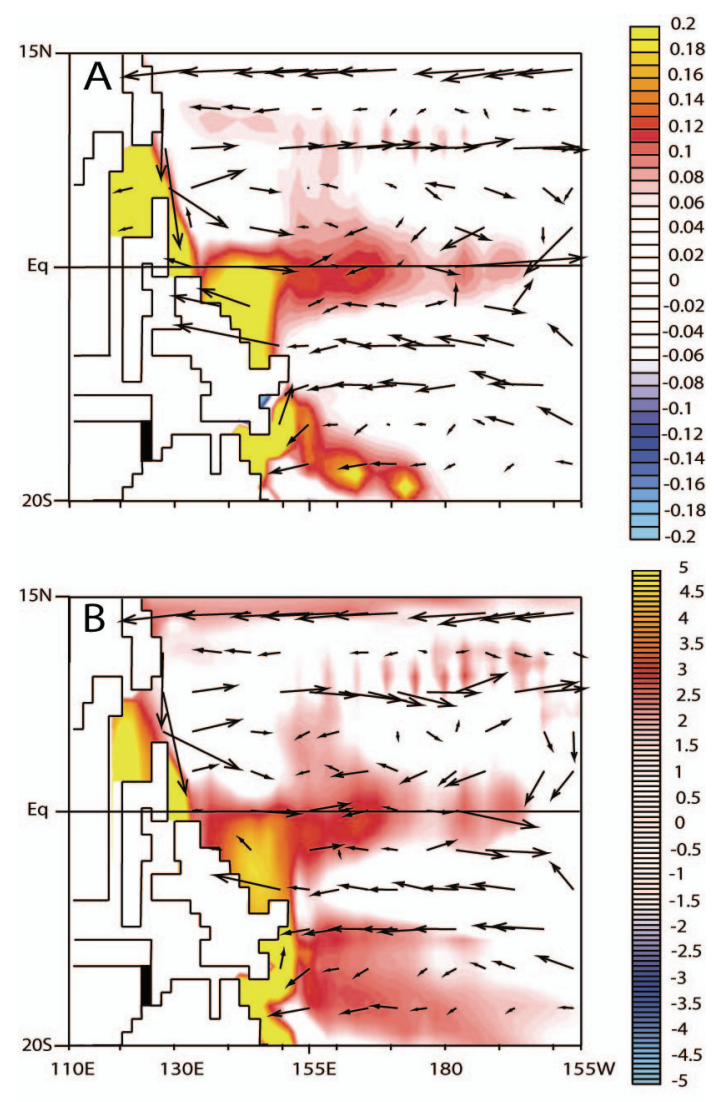

Fig 1: (A) Difference (ITC-REF) of the mean iron concentration (nM) between the isopycnal surfaces $\sigma_{\theta}=23.5 \mathrm{~kg} \cdot \mathrm{m}^{-3}$ and $\sigma_{\theta}=25.5 \mathrm{~kg} \cdot \mathrm{m}^{-3}$. Vectors represent the currents $\left(\mathrm{m} . \mathrm{s}^{-}\right.$ ${ }^{1}$ ) averaged between the previous isopycnal surfaces for REF. (B) As for A but with nitrate $(\mu \mathrm{M})$ rather than iron and with ITC currents rather than REF currents. The black region is added in the Timor strait to close the ITF for the ITC simulation. 

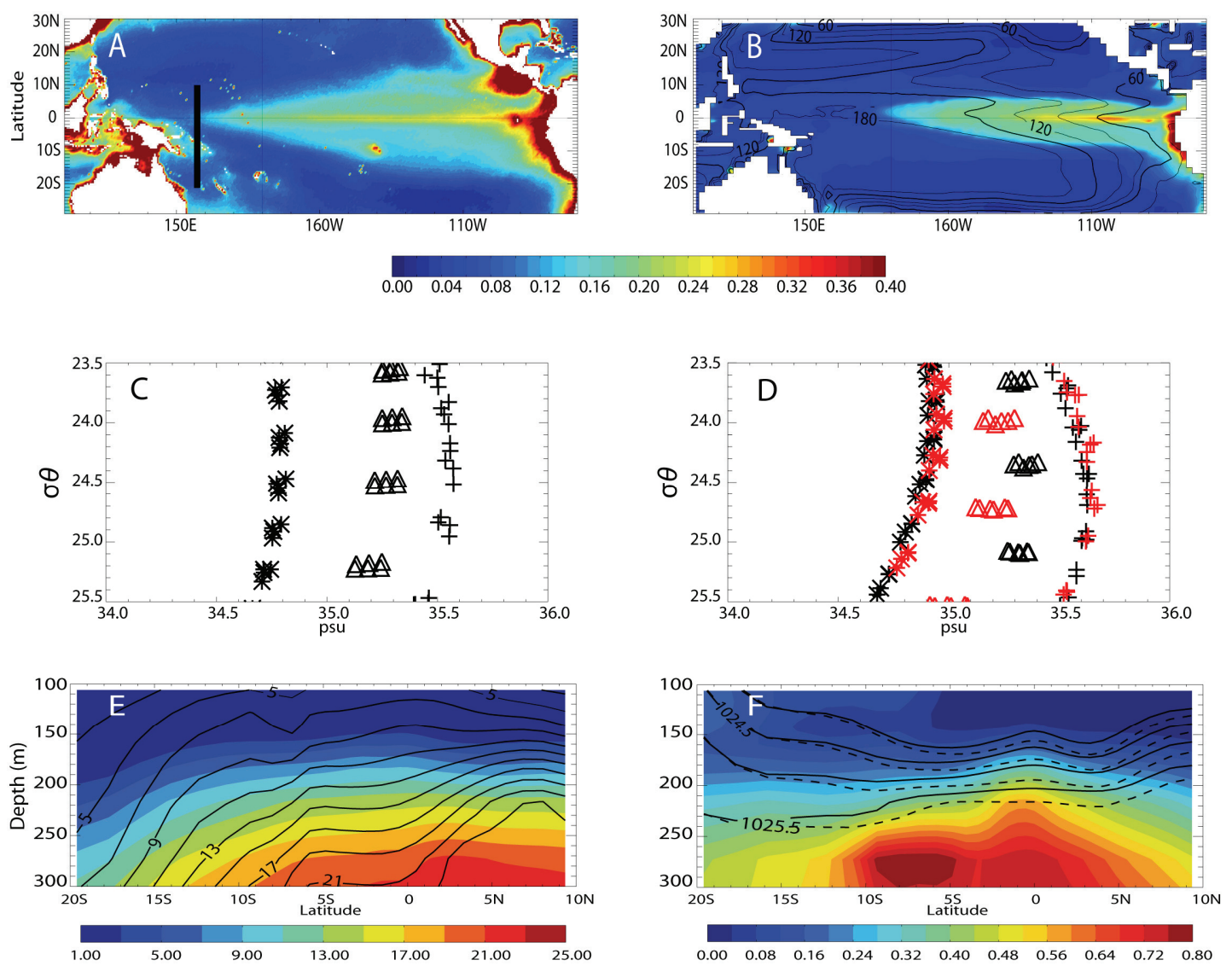

Fig 2: (A) Mean SeaWiFS chlorophyll concentration (mg.m ${ }^{-3}$ ) over the 1999-2004 period compared to (B) the climatological concentration of our reference simulation with the depth of the $20^{\circ} \mathrm{C}$ isotherm plotted over. (C) Salinity versus density diagram for the SHW (cross), the NHW (stars) and the EUC waters (triangle) for the WOA98 data. (D) As for $\mathrm{C}$, but for our two simulations (REF=blue; $\mathrm{ITC}=$ red). (E) Meridional section at $155^{\circ} \mathrm{E}$ of the nitrate concentration $(\mu \mathrm{M})$ for the REF simulation (colors) and the data from the WOA98 (black lines). (F) Meridional section at 155E of the iron concentration (nM) with isopycnal surfaces from REF (black lines) and from ITC (dashed lines). 

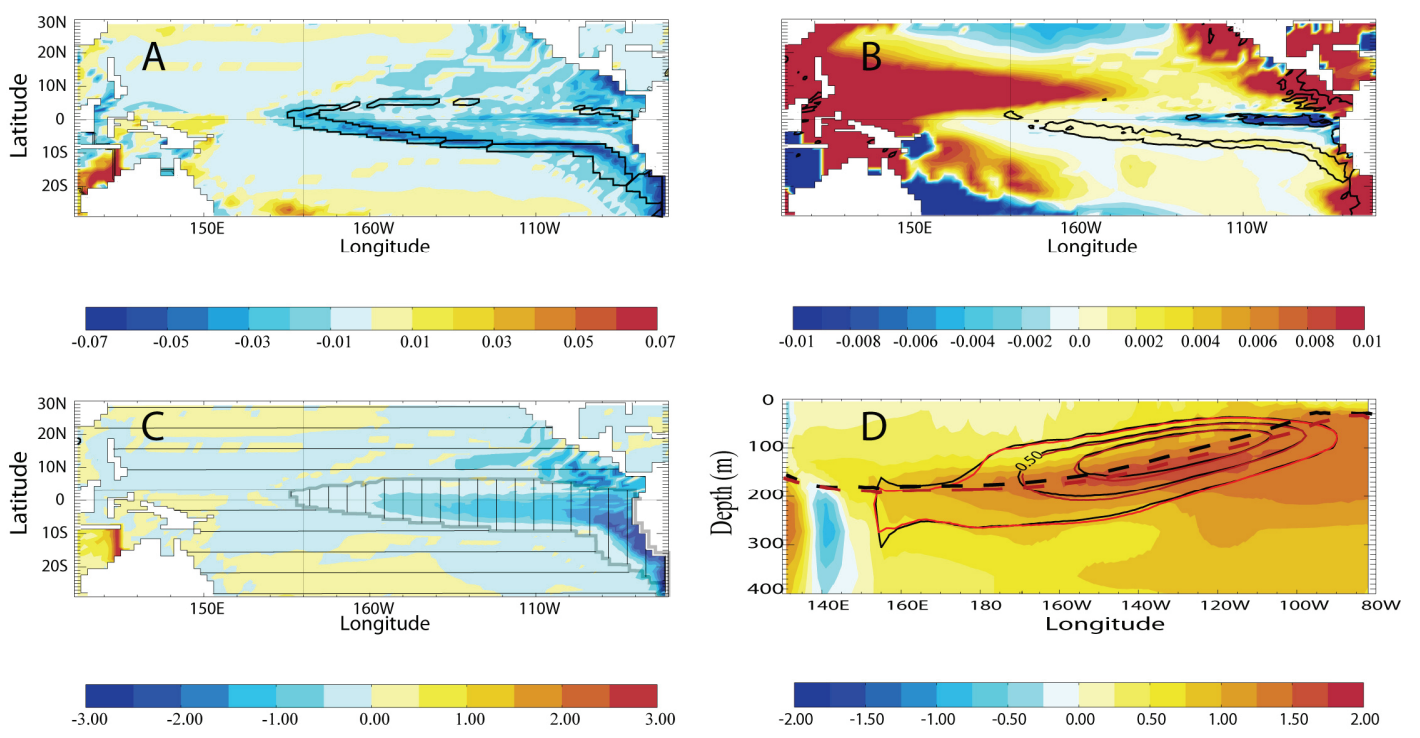

Fig 3: (A) Difference (ITC-REF) of chlorophyll concentration (mg. $\left.\mathrm{m}^{-3}\right)$ averaged over the depth of the euphotic zone. Contour indicates the change in areal extent (ITC-REF) of the region where nitrate is the limiting nutrient. (B) As for A, but for iron (nM) concentration. The contour of $0.03 \mathrm{mg} . \mathrm{m}^{-3}$ of chlorophyll difference is added. (C) As for $\mathrm{B}$, but for nitrate $(\mu \mathrm{M})$ rather than iron and with vertical (horizontal) hatch marks which indicate the iron (nitrate) limited region in the REF simulation. (D) Vertical section at the equator of the temperature difference (ITC-REF). Closed contours show the EUC zonal the $20^{\circ} \mathrm{C}$ isotherm depth from REF (ITC). 